University of Nebraska - Lincoln

DigitalCommons@University of Nebraska - Lincoln

Mechanical \& Materials Engineering Faculty

Publications

Mechanical \& Materials Engineering

Department of

2011

Assessment of Shape Memory Alloy Stent Deployment in a Stenosed Artery

\author{
Shijia Zhao \\ University of Nebraska-Lincoln \\ Linxia Gu \\ University of Nebraska-Lincoln, gul@fit.edu \\ Stacey R. Froemming \\ Children's Hospital \& Medical Center, Omaha, NE
}

Follow this and additional works at: https://digitalcommons.unl.edu/mechengfacpub

Part of the Mechanical Engineering Commons

Zhao, Shijia; Gu, Linxia; and Froemming, Stacey R., "Assessment of Shape Memory Alloy Stent Deployment in a Stenosed Artery" (2011). Mechanical \& Materials Engineering Faculty Publications. 59.

https://digitalcommons.unl.edu/mechengfacpub/59

This Article is brought to you for free and open access by the Mechanical \& Materials Engineering, Department of at DigitalCommons@University of Nebraska - Lincoln. It has been accepted for inclusion in Mechanical \& Materials Engineering Faculty Publications by an authorized administrator of DigitalCommons@University of Nebraska Lincoln. 


\title{
Assessment of Shape Memory Alloy Stent Deployment in a Stenosed Artery
}

\author{
Shijia Zhao, ${ }^{1}$ Linxia Gu, ${ }^{1,2}$ and Stacey R. Froemming ${ }^{3}$ \\ 1. Department of Mechanical \& Materials Engineering, University of Nebraska-Lincoln, Lincoln, NE 68588, USA \\ 2. Nebraska Center for Materials and Nanoscience, Lincoln, NE 68588, USA \\ 3. Hybrid Catheterization \& Electrophysiology Laboratory, Children's Hospital \& Medical Center, Omaha, NE \\ 68114, USA \\ Corresponding author - L. Gu, tel 402-472-7680, fax 402-472-1465, email lgu2@unl.edu
}

\begin{abstract}
Purpose - Shape memory alloy (SMA) stents have been used increasingly for the treatment of complex arterial occlusions. There is an immediate need to quantify the mechanical performance of SMA stents to open occluded arteries.

Methods - The stent crimping and expanding process was assessed through both numerical modeling and in-vitro studies. The implantation of a SMA stent in curved arteries with eccentric stenosis were simulated to evaluate the effect of artery curvature on arterial mechanics.

Results - The crimping process stored a considerable amount of strain energy in the stent, which were then released through self-expansion until a balance between the stent and stenosed artery was achieved. The deployed SMA stent exhibited a dog-bone shape, where the longitudinal ends of the stent penetrated into the artery causing arterial stress concentrations. However, the maximum arterial stress was observed at the central portion of artery contacting the thin side of the plaque. Furthermore, stent-induced arterial mechanics were more pronounced in the curved artery than the straight artery. The maximum Von Mises stress in the curved artery with a curvature of $0.05 \mathrm{~mm}^{-1}$ was $37 \%$ larger than that found in the straight artery. The percentage of the intimal area at higher stress level (> $0.05 \mathrm{MPa})$ is $5.51 \%$ in the curved artery, compared to $1.76 \%$ in the straight artery.

Conclusions - This work provided a fundamental understanding of the behavior of SMA stent and its impact on the vascular wall, and illuminated the possibilities for exploiting their potential to alleviate arterial injury.
\end{abstract}

Keywords: shape memory alloy, stenting, finite element method, curved artery, eccentric stenosis

\section{Introduction}

Computational methods have been widely used to estimate the performance of stenting procedures and their clinical implications. Balloon-expandable stents and their interaction with stenosed arteries have been extensively investigated through finite element methods [1-7]. However, the Ni-Ti shape memory alloy (SMA) stents have been less thoroughly studied. Several previous numerical studies have focused on the SMA stents deployed inside a straight artery [8-10] or in an anatomically accurate artery without stenosis $[11,12]$. Wu et al. [13] simulated the delivery and release of an Ni-Ti SMA stent in a curved carotid artery with 33\% stenosis, which is not typically clinically significant for stent implantation. A detailed evaluation of Ni-Ti SMA stents deployed in eccentric stenoses is, however, lacking. Thus, the objective of this work is to assess the impact of the implantation of a PROTÉGÉTM GPSTM Ni-Ti SMA stent (ev3 Inc., Plymouth, MN, USA) in a curved artery with eccentric stenosis. The crimping and expanding process of the stent was presented and discussed. Furthermore, a corresponding less curved artery model and straight artery model with eccentric stenosis were proposed and investigated to evaluate the influence of artery curvature on stent-artery interaction, particularly on arterial stress distribution after stenting.

\section{Materials and Methods}

\section{Constitutive models}

Porcine pulmonary arteries from three domestic piglets were cleared of any visible lipid deposition before being cut into 12 rectangular strips along circumferential 
and axial directions. Uniaxial tension tests were conducted using the computer-controlled tissue testing machine (Test Resource Inc., Shakopee, MN, USA). Displacement control with a ramping rate of $0.05 \mathrm{~mm} / \mathrm{s}$ was used to deform the specimens. Force and displacement data were recorded throughout the test at a frequency of $20 \mathrm{~Hz}$. Based on these data and original dimensions, the nominal stress and strain were calculated and plotted. In addition, the local strains of the specimen during the tension tests were captured and measured using the ARAMIS stereo optical surface strain measurement system (Trilion Quality Systems, Plymouth Meeting, PA, USA). Previous work [14] has demonstrated that simply calculated nominal strain agreed very well with the surface-averaged local strain measurements obtained using the ARAMIS system.

The uniaxial tension test data were used to construct a reduced third-order hyperelastic polynomial constitutive model, which is expressed with the strain energy density function $U$ as

$$
U=\sum_{i+j=1}^{N} C_{i j}\left(I_{1}-3\right)^{i}\left(I_{2}-3\right)^{j}
$$

where $C_{i j}$ are material coefficients determined from the experimental data. $I_{1}$ and $I_{2}$ are the first and second invariant of the Cauchy-Green tensor, defined respectively as $I_{1}=\lambda_{1}^{2}+\lambda_{2}^{2}+\lambda_{3}^{2}$ and $I_{2}=\lambda_{1}^{-2}+\lambda_{2}^{-2}+\lambda_{3}^{-2}$ where $\lambda_{i}$ are the principal stretches.

The least square method was used to fit this test data and obtain the material coefficients of the artery as $\mathrm{C}_{10}$ $=0.01488 \mathrm{MPa}, \mathrm{C}_{20}=0.01492 \mathrm{MPa}$, and $\mathrm{C}_{30}=0.000939$ $\mathrm{MPa}$. The material properties of plaque were adopted from the documented literatures [9], with coefficients of $\mathrm{C}_{10}=0.04 \mathrm{MPa}, \mathrm{C}_{02}=0.003 \mathrm{MPa}$, and $\mathrm{C}_{03}=0.02976 \mathrm{MPa}$.

The GPSTM stent is made of the Ni-Ti SMA material, associated with stress-induced transformations between the austenite and martensite phases. The material parameters for the isothermal superelastic behavior of NiTi SMA [15], as seen in Figure 1, were implemented in the ABAQUS user material subroutine (VUMAT).

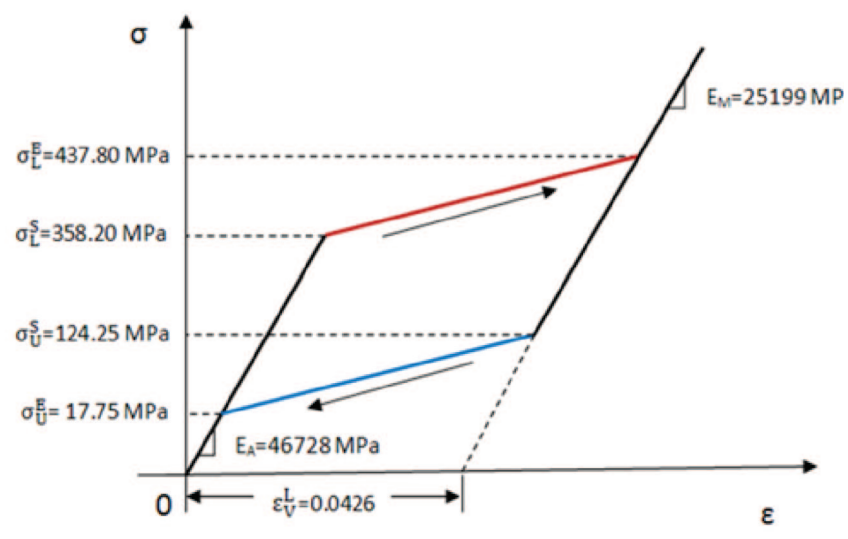

Figure 1. The mechanical behavior of Ni-Ti SMA.

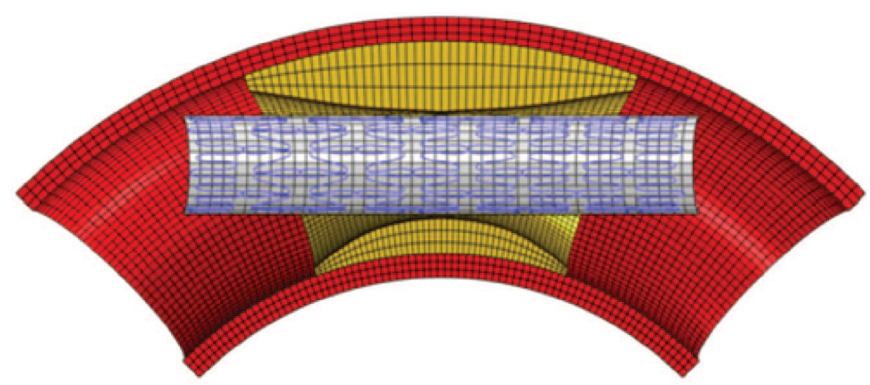

Figure 2. Sectional model of a stenosed artery, including a PROTÉGÉT ${ }^{\mathrm{TM}}$ GPSTM stent confined inside a sheath.

\section{Finite element modeling}

Three-dimensional models simulating stent crimping and self-expansion in an eccentric stenosed artery were developed using the finite element software, ABAQUS Version 6.10 (Dassault Systèmes Simulia Corp., Providence, RI, USA). A 50\% stenosed artery with curvature of $0.05 \mathrm{~mm}^{-1}$ was used based on the anatomy of the coronary artery [16]. The inner diameter of the artery is 9 $\mathrm{mm}$ with a wall thickness of $1 \mathrm{~mm}$. Figure 2 has demonstrated that the PROTÉGÉTM GPSTM Ni-Ti SMA stent was confined within the sheath, a rigid thin shell with a length of $22 \mathrm{~mm}$. After it was delivered to the targeted lesion site, a ramping velocity of $4000 \mathrm{~mm} / \mathrm{s}$ was applied to the sheath for removal. The sheath removal and stent self-expansion process, as depicted in Figure 3, was obtained from an in-vitro test. A friction coefficient of 0.15 was prescribed among all contact surfaces. Mesh convergence studies were performed using maximum

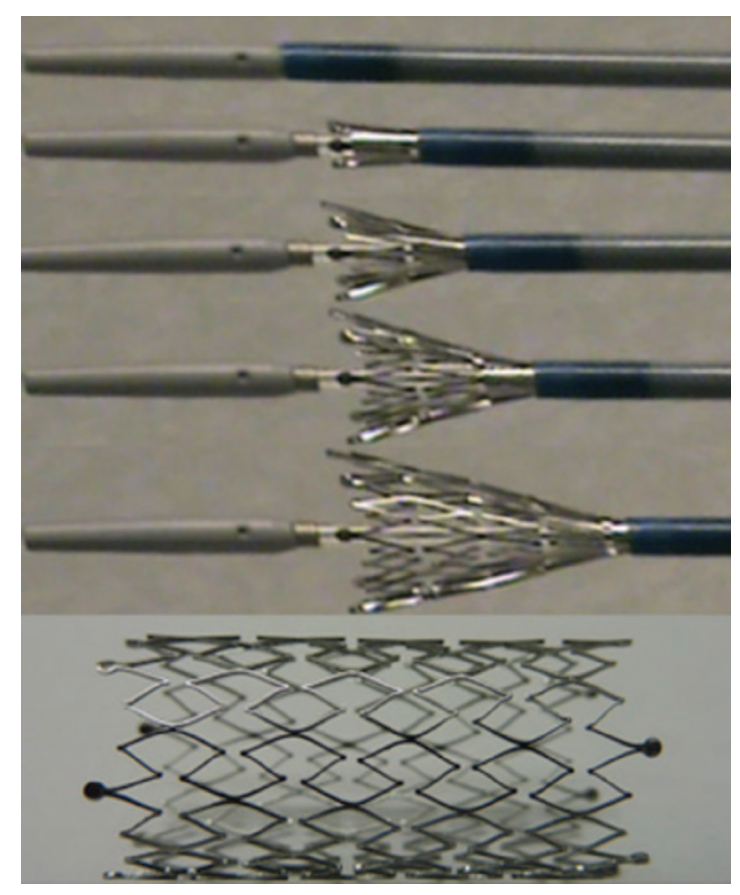

Figure 3. Expansion process of a PROTÉGÉTM GPSTM Ni-Ti stent. 
radial displacement as an evaluation standard to decide the element number of the artery. The stent was meshed using 7248 two-node linear beam elements, B31. The sheath was discretized with 1118 reduced four-node shell elements (S4R), while the artery and plaque were meshed with 18960 and 11592 reduced eight-node brick elements (C3D8R), respectively.

\section{Results and Discussions}

\section{Stent crimping process}

The stent crimping was achieved by applying a uniform radial displacement boundary condition on the whole stent until it was confined inside the sheath. During crimping, the corresponding resultant force provided information on the ability of the stent to push the lesion outward when deployed inside a stenosed vessel. The resultant force, also referred to as the stent strength, is calculated as $p s / \pi$, where $p$ is the equivalent pressure applied on the stent and $s$ is the area of outer surface of stent. It is worth noting that the resultant force is linearly proportional to the equivalent pressure. The relationship between resultant force and stent diameter is depicted in Figure 4, which exhibits a larger strength for increasingly smaller stent sizes. This can

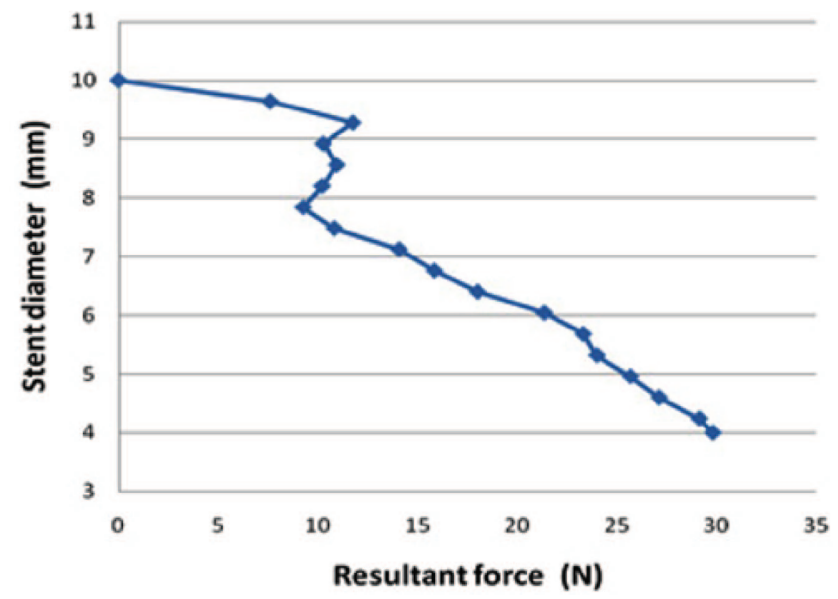

Figure 4. The strength vs. diameter of stent during crimping. be used to understand the $0.5-1.5 \mathrm{~mm}$ diameter overexpansion requirement indicated in the stent manual. The characteristic sections in Figure 4 correspond to the elastic deformation of austenite, the austenite to martensite transformation and the elastic deformation of martensite, respectively. Once the stent is confined inside the sheath, the end of the crimping process led to the largest strain on the stent, as seen in Figure 5. The peak principal logarithm strain of $4.88 \%$ occurred around the connecting struts, which is less than its critical strain limit of $12 \%$. The crimping process stored a considerable amount of strain energy in the stent as depicted in Figure 6 . The establishment of contact between the stent and sheath in step 2 consumed a smaller amount of the strain energy, and the majority of the stored energy was used for stent self-expansion to reopen the occluded lumen until equilibrium between the stent and the stenosed artery was achieved.

\section{Stent self-expansion in a curved artery}

The deployment of the ProtégéT ${ }^{\mathrm{TM}}$ GPSTM Ni-Ti stent reopened the occluded curved vessel, as seen in Figure 7a. Following the self-expansion of the stent, the minimum lumen diameter increased from $4.5 \mathrm{~mm}$ to $7.9 \mathrm{~mm}$ immediately. The stent did not restore its nominal diameter of $10 \mathrm{~mm}$, instead exhibiting a dog-bone shape

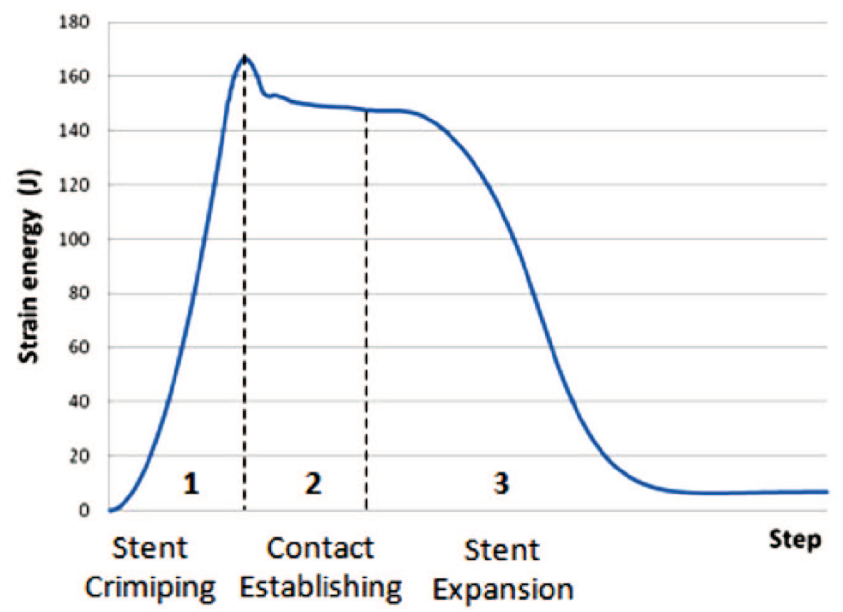

Figure 6. The strain energy of stent during analysis.

\begin{tabular}{|l|}
\hline LE, Max. Principal \\
Multiple section points \\
(Avg: $75 \%$ ) \\
$\begin{array}{r}+4.877 \mathrm{e}-02 \\
+4.471 \mathrm{e}-02 \\
+4.064 \mathrm{e}-02 \\
+3.658 \mathrm{e}-02 \\
+3.252 \mathrm{e}-02 \\
+2.845 \mathrm{e}-02 \\
+2.439 \mathrm{e}-02 \\
+2.032 \mathrm{e}-02 \\
+1.626 \mathrm{e}-02 \\
+1.219 \mathrm{e}-02 \\
+8.129 \mathrm{e}-03 \\
+4.064 \mathrm{e}-03 \\
+1.396 \mathrm{e}-13\end{array}$ \\
\hline
\end{tabular}

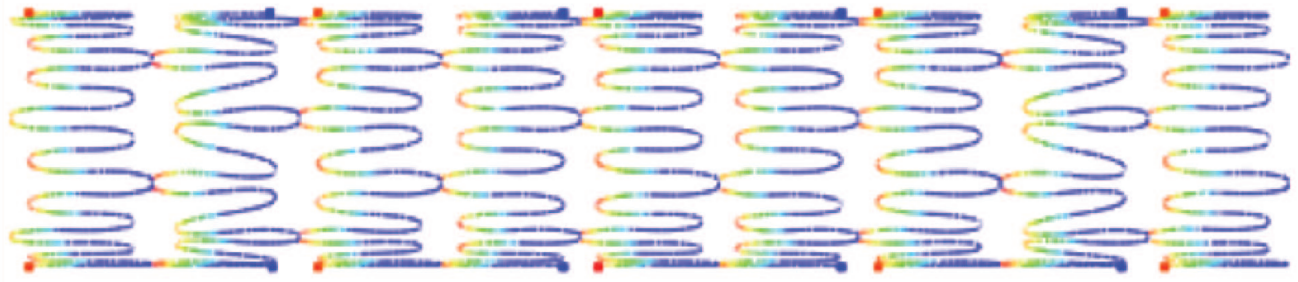

Figure 5. The principal strain field of the crimped stent. 

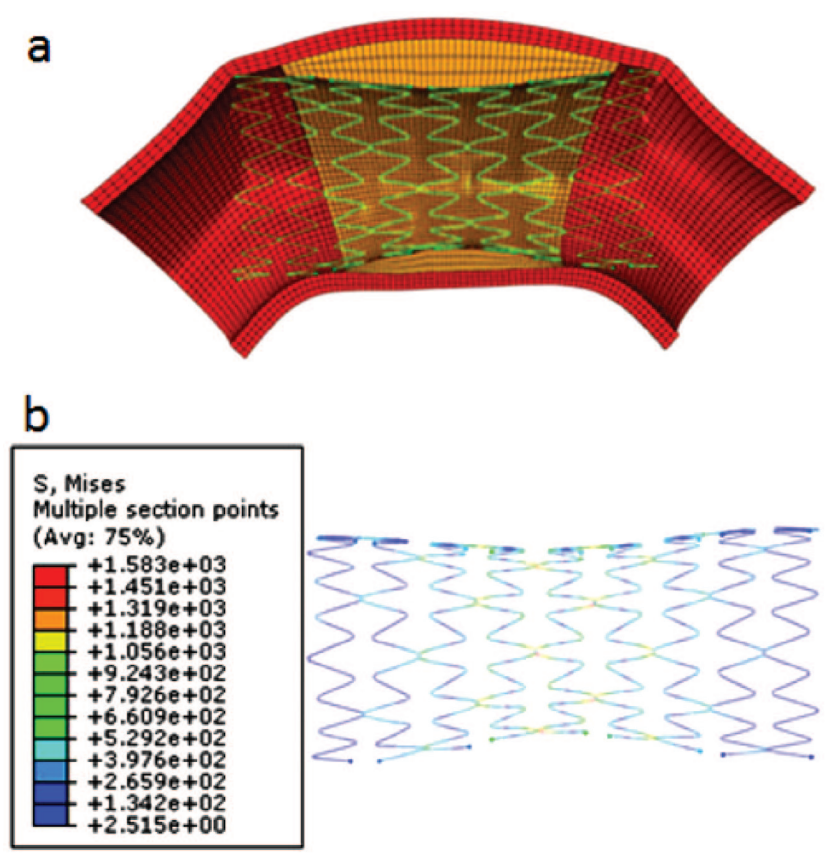

Figure 7. (a) The deployment of stent inside a curved artery with eccentric stenosis. (b) The stress map on the stent after expansion.

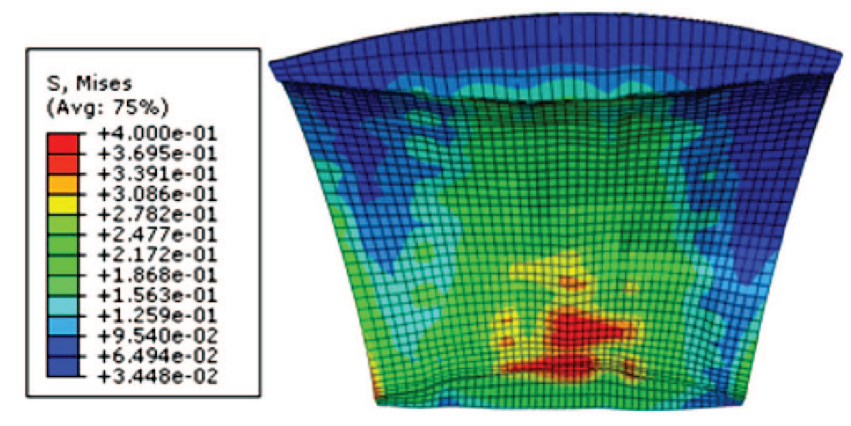

Figure 8. The stress distribution on plaque after self-expansion of stent in curved artery.

with diameters of $8.03 \mathrm{~mm}, 9.76 \mathrm{~mm}$ and $9.90 \mathrm{~mm}$ at the center, proximal end and distal end of stent, respectively. Correspondingly, the stent length was slightly increased to $21.49 \mathrm{~mm}$ from the nominal value of $20 \mathrm{~mm}$. It is obvious that Von Mises stress experienced by the stent approached zero at the two extremes and the peak stress occurred at the central portion of the stent, particularly around the connector or transiting corner (Figure $7 \mathrm{~b}$ ). This implies that the geometry of the connector and adjacent struts may directly affect the strength of the stent design. The minimum lumen cross-sectional area enclosed by the stent was calculated to be 51.53 $\mathrm{mm}^{2}$; while the proximal and distal reference lumen areas are $79.77 \mathrm{~mm}^{2}$ and $81.69 \mathrm{~mm}^{2}$, respectively. The ratio of minimum stent area to the average proximal and distal reference lumen area is $64 \%$, which is less than
$80 \%$, indicating the occurrence of underexpansion [17, 18]. This phenomenon is speculated to be closely related to stent thrombosis and in-stent restenosis [19]. Many factors may contribute to the underexpansion of the stent, such as the relatively low stiffness of Ni-Ti SMA (47 GPa) [13] in comparison with conventional stainless steel (190 GPa) or cobalt chromium (243 GPa), the nonuniform plaque distribution along the axial direction [20], or the stent configuration.

The underexpansion of the stent caused the struts to not fully contact and support the arterial wall, especially around the plaque edge, which is also referred to as an incomplete stent apposition (ISA). An ISA area, defined as the area of noncontact tissue underlying the stent, was calculated to be $193.5 \mathrm{~mm}^{2}$ in our model. ISA may be a predictor of a higher possibility of late stent thrombosis, especially for drug-eluting stents [13, 21, 22]. Both underexpansion and ISA could be corrected during intervention through post balloon dilation subsequent to Ni-Ti stenting in order to reduce the instant underexpansion and improve the apposition area [5]. On the other hand, continuous expansion has been observed in $\mathrm{Ni}-\mathrm{Ti}$ stents in the period following the surgical procedure, from 48 hours up to 9 months, due to temperature dependent phase transformation. This phenomenon might alleviate the underexpansion and also compensate the lumen loss caused by neointimal hyperplasia.

Deployment of the stent led to the compression of the plaque, an overstretching of the arterial wall and induced stress concentrations on the lesion, which contributed to the occurrence of in-stent restenosis. The Von Mises stress distributions on the plaque were reported in Figure 8. It is interesting to note that the observed peak stresses, ranging from $0.35 \mathrm{MPa}$ to 0.4 $\mathrm{MPa}$, concentrated in the area of the thin side contacting with the stent struts, where plaque fracture might be initiated [23]. Correspondingly, the peak Von Mises stress on the arterial wall is also located at the central segment contacting the thin side of the plaque, as seen in Figure 9. This implies that the complications of stenting may be initiated from the thinner side of the lesion. It is also worth noting that the stent ends protruded into the arterial wall and induced stress concentrations at the contacting section. This trend was more prominent in the curved artery than in the straight one, as seen in Figure 9.

\section{Effect of curvature on arterial mechanics}

The effect of arterial curvature on stent-induced arterial stress distributions was evaluated through varying the arterial curvature from $0.05 \mathrm{~mm}-1$ (most curved artery), $0.04 \mathrm{~mm}^{-1}$ (less curved artery) to $0 \mathrm{~mm}^{-1}$ (straight artery), as shown in Figure 9. It is obvious that the Ni-Ti stent induced larger Von Mises stresses and high-stress coverage on the intimal surface of artery with larger curvature. The maximum Von Mises stress is $0.074 \mathrm{MPa}$ 


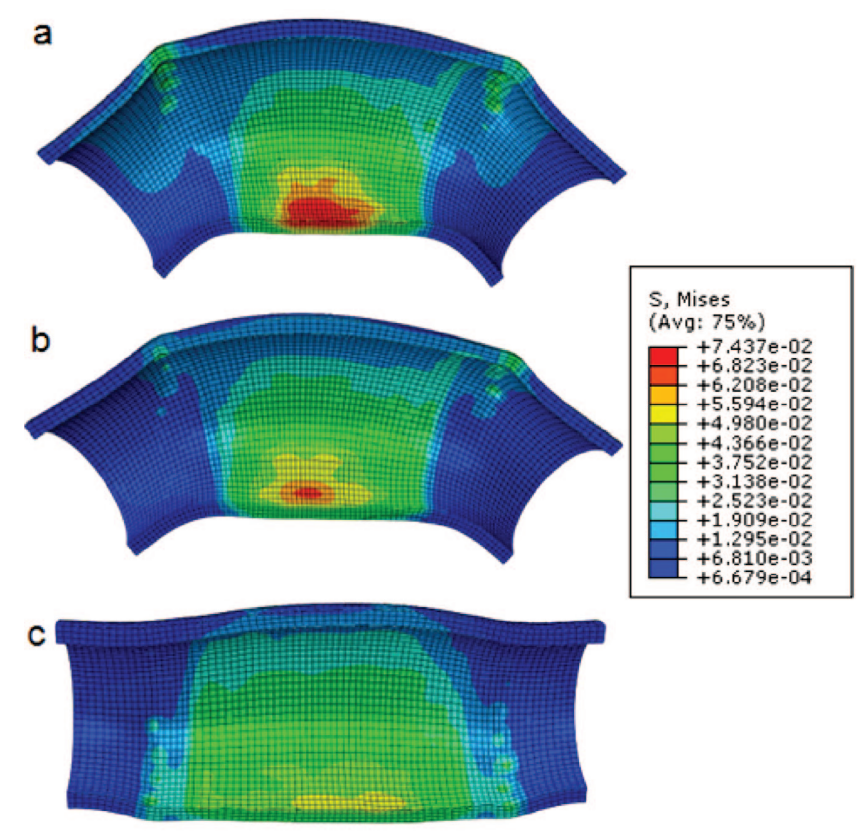

Figure 9. The stress distribution on arteries. (a) Artery with curvature of $0.05 \mathrm{~mm}^{-1}$. (b) Artery with curvature of $0.04 \mathrm{~mm}^{-}$ 1. (c) Straight artery.

on the most curved artery, which is $16 \%$ and $37 \%$ larger than the peak stress on the less curved artery and straight artery, respectively. All peak stresses are located under the thin side of the plaque, indicating a lower resistance from the thin side of the plaque. For Von Mises stresses larger than $0.05 \mathrm{MPa}$, the percentage of intimal area is $5.51 \%$ in the most curved artery, while it is $2.36 \%$ and $1.76 \%$ in the less curved artery and straight artery, respectively. It was also noticed that stress concentrations occurred at the stent ends in all arteries regardless of its curvature. The peak Von Mises stress at the hinge points contacting with stent ends in the most curved artery was found to be $0.053 \mathrm{MPa}$, while it is $0.047 \mathrm{MPa}$ in the less curved artery and $0.031 \mathrm{MPa}$ in the straight artery. This could be explained by the material and geometrical mismatch between stent and lesions as stents tend to straighten artery during expansion. The higher stress and stress gradient on the most curved vessel contacting ends of the stent indicates a severer hinge effect than found in the less curved vessel including straight vessel, which may trigger the neointima proliferation and in turn increase the possibility of restenosis [23]; meanwhile, the risk of edge dissection might be high in a curved vessel with larger curvature [24, 25].

\section{Limitations}

This work investigated the crimping and deployment of Ni- Ti SMA stents in a curved stenotic artery along with its acute outcome. Various stent performance indicators, including its strain energy recovery, radial strength, dog-bone effect, ISA, stress distribution on the lesions were discussed. In addition, the influence of arterial curvature was demonstrated by juxtaposition with a corresponding less curved and straight artery case. The main limitation of this study is that blood flow was not included. Both the artery and plaque are idealized representations of a stenosed artery. An image-based artery and plaque model may be a good practice for surgical planning; however, the complicated stress map on the artery wall is not easily inferred, which is not appropriate for understanding the physics of the curvature effect. Isotropic hyperelastic material models were adopted to describe the mechanical response of the artery and plaque, though the lesion generally exhibits an anisotropic mechanical response [26, 27]. The superelasticity of Ni-Ti stents is considered as isothermal in this work, and the thermal-mechanical response for $\mathrm{Ni}$ Ti SMA was not modeled, which limited this work to modeling a continuous expansion after immediate stent deployment.

\section{Acknowledgments}

The support of the National Science Foundation under grant No. 0926880 is gratefully acknowledged.

\section{References}

[1] Bedoya J, Meyer CA, Timmins LH, Moreno MR, Moore JE. Effects of stent design parameters on normal artery wall mechanics. J Biomech Eng. 2006; 128(5):757-65.

[2] Holzapfel GA, Stadler M, Gasser TC. Changes in the mechanical environment of stenotic arteries during interaction with stents: computational assessment of parametric stent designs. J Biomech Eng. 2005; 127(1):166-80.

[3] Lally C, Dolan F, Prendergast PJ. Cardiovascular stent design and vessel stresses: a finite element analysis. J Biomech. 2005; 38(8):1574-81.

[4] Park WP, Cho SK, Ko JY, Kristensson A, Al-Hassani STS, Kim HS, Lim D. Evaluation of stent performances using FEA considering a realistic balloon expansion. Int $J$ Eng Phys Sci. 2008; 2(2):103-8.

[5] Pericevic I, Lally C, Toner D, Kelly DJ. The influence of plaque composition on underlying arterial wall stress during stent expansion: the case for lesion-specific stents. Med Eng Phys. 2009; 31(4):428-33.

[6] De Beule M, Mortier P, Carlier SG, Verhegghe B, Van Impe $\mathrm{R}$, Verdonck P. Realistic finite element-based stent design: the impact of balloon folding. J Biomech. 2008; 41(2):383-9.

[7] Zahedmanesh H, John Kelly D, Lally C. Simulation of a balloon expandable stent in a realistic coronary artery-determination of the optimum modelling strategy. J Biomech. 2010; 43(11):2126- 32.

[8] Kleinstreuer C, Li Z, Basciano CA, Seelecke S, Farber MA. Computational mechanics of nitinol stent grafts. J Biomech. 2008; 41(11):2370-8. 
[9] Migliavacca F, Petrini L, Massarotti P, Schievano S, Auricchio F, Dubini G. Stainless and shape memory alloy coronary stents: a computational study on the interaction with the vascular wall. Biomech Model Mechanobiol. 2004; 2(4):205-17.

[10] Kim JH, Kang TJ, Yu WR. Simulation of mechanical behavior of temperature-responsive braided stents made of shape memory polyurethanes. J Biomech. 2010; 43(4):632-43.

[11] Conti M, Auricchio F, De Beule M, Verhegghe B. Numerical simulation of Nitinol peripheral stents: from laser-cutting to deployment in a patient specific anatomy. ESOMAT. 2009; doi: 10.1051/esomat/200906008.

[12] Rebelo N, Fu R, Lawrenchuk M. Study of a nitinol stent deployed into anatomically accurate artery geometry and subjected to realistic service loading. J Mater Eng Perform. 2009; 18(5-6):655-63.

[13] Wu W, Qi M, Liu XP, Yang DZ, Wang WQ. Delivery and release of nitinol stent in carotid artery and their interactions: a finite element analysis. J Biomech. 2007; 40(13):3034-40.

[14] Zhao SJ, Gu LX, Hammel JM, Lang HL. Mechanical behavior of porcine pulmonary artery. Proc ASME IMECE 2010. 2010; 39012.

[15] Rebelo N, Walker N, Foadian H. Simulation of implantable nitinol stents. Conf Proc Abaqus Users. 2001.

[16] Prosi M, Perktold K, Ding Z, Friedman MH. Influence of curvature dynamics on pulsatile coronary artery flow in a realistic bifurcation model. J Biomech. 2004; 37(11):1767-75.

[17] Uren NG, Schwarzacher SP, Metz JA, Lee DP, Honda Y, Yeung AC, Fitzgerald PJ, Yock PG. Predictors and outcomes of stent thrombosis. Eur Heart J. 2002; 23(2):124-32.

[18] Cheneau E, Satler LF, Escolar E, Suddath WO, Kent KM, Weissman NJ, Waksman R, Pichard AD. Underexpansion of sirolimus-eluting stents: incidence and relationship to delivery pressure. Catheter Cardio Inte. 2005; 65(2):222-6.
[19] Fujii K, Carlier SG, Mintz GS, Yang YM, Moussa I, Weisz G, Dangas G, Mehran R, Lansky AJ, Kreps EM, Collins M, Stone GW, Moses JW, Leon MB. Stent underexpansion and residual reference segment stenosis are related to stent thrombosis after sirolimus-eluting stent implantation: an intravascular ultrasound study. J Am Coll Cardiol. 2005; 45(7):995-8.

[20] Kan HC. Investigation of plaque effects on cardiovascular stent system. iCBBE. 2010; doi: 10.1109/ ICBBE.2010.5516850.

[21] Cook S, Wenaweser $P$, Togni $M$, Billinger $M$, Morger C, Seiler C, Vogel R, Hess O, Meier B, Windecker S. Incomplete stent apposition and very late stent thrombosis after drug-eluting stent implantation. Circulation. 2007; 115(18):2426-34.

[22] Pfisterer ME. Late stent thrombosis after drug-eluting stent implantation for acute myocardial infarction: a new red flag is raised. Circulation. 2008; 118(11):1117-9.

[23] Timmins LH, Meyer CA, Moreno MR, Moore JE. Effects of stent design and atherosclerotic plaque composition on arterial wall biomechanics. J Endovasc Ther. 2008; 15(6):643-54.

[24] Liao R, Green NE, Chen SY, Messenger JC, Hansgen AR, Groves BM, Carroll JD. Three-dimensional analysis of in vivo coronary stent--coronary artery interactions. Int J Carduivasc Imaging. 2004; 20(4):305-13.

[25] Colombo A, Stankovic G, Moses JW. Selection of coronary stents. J Am Coll Cardiol. 2002; 40(6):1021-33.

[26] Gamero AM, Armentano RL, Levenson J. Arterial wall diameter and viscoelasticity variability. Comput Cardiol. 2002; 29:513-6.

[27] Moore JE, Berry JL. Fluid and solid mechanical implications of vascular stenting. Ann Biomed Eng. 2002; 30(4):498-508 